\title{
Proposta de metodologia para generalização cartográfica para mapeamento topográfico de áreas urbanas
}

\author{
Mônica Cristina de Castro* \\ Claudia Robbi Sluter**
}

Recebido 15 de julho de 2014; aceito 18 de julho de 2014

\begin{abstract}
Cartographic generalization can be describe as a process which preserves the characteristics of the features represented on a map, when its scale is reduced, in a way that the user can easily understand the information presented. It is a process of quantitative and qualitative adaptation. The production of topographic maps in different scales by generalization is performed in many countries, and this makes the production and the actualization of basic maps more efficient. Set in the generalization context, this research aims to define a methodology to represent buildings, property boundaries and street features in scale 1:5.000 by generalization of the topographic maps in scale 1:2.000. This was made by the analysis of the feature classes in reduced scale, identification of the representation problems, definition and application of the generalization operators. The results were achieved using ArcMap and the generalization operators of elimination, simplification and amalgamation. Each one was applied according to the representation problem. Manual generalization it is a subjective and intuitive process, then the results depend on the generalization operators and the degree of their application, and these factors are consequential of the decisions taken by the cartographer.
\end{abstract}

Key words: cartographic generalization, topographic map, generalization operators.

* Departamento de Geomática da Universidade Federal do Paraná, Mestranda do Curso de Pós-Graduação em Ciências Geodésicas, Caixa Postal 19001, Centro Politécnico, 81531990, Curitiba, Paraná, e-mail: castro.monicac@gmail.com

** Departamento de Geomática da Universidade Federal do Paraná, Curso de Engenharia Cartográfica, Curso de Pós-Graduação em Ciências Geodésicas, Curitiba, Paraná, e-mail: robbi@ufpr.br 


\section{Resumen}

La generalización cartográfica consiste en la preservación de las características de los elementos representados en una carta topográfica cuando su escala es reducida, de forma que la información pueda ser comprendida fácilmente por el usuario; en otras palabras, es un proceso de adaptación cuantitativo y cualitativo. La elaboración de cartas topográficas en diferentes escalas a través de generalización es realizada en varios países, haciendo más eficiente la producción y actualización del mapeo base. Dentro del contexto de generalización, este trabajo tiene como objetivo definir una metodología para la representación de edificaciones, límites de propiedades y vías en escala 1:5.000, por generalización de cartas topográficas en escala 1:2.000. Esto fue realizado por medio de un análisis de las clases de los elementos presentes en la escala reducida, así como de la identificación de los problemas de representación, y de la definición y aplicación de los operadores de generalización cartográfica. Los resultados se alcanzaron utilizando el software ArcMap y los operadores de generalización: eliminación, simplificación y amalgamado, de acuerdo con cada problema de representación detectado. La generalización manual es un proceso subjetivo e intuitivo, por esta razón el resultado depende de los operadores de generalización y del grado de aplicación de los mismos, siendo estos factores consecuencia de las decisiones tomadas por el cartógrafo.

Palabras clave: generalización cartográfica, carta topográfica, operadores de generalización.

\section{Resumo}

A generalização cartográfica consiste num proceso de preservação das características das feições representadas numa carta quando esta tem sua escala reduzida, de modo que as informações possam ser compreendidas facilmente pelo usuário, ou seja, é um processo de adaptação, quantitativo e qualitativo. A elaboração de cartas topográficas em diferentes escalas por generalização é realizada em muitos países, tornando a produção e atualização do mapeamento básico mais eficiente. Inserida no contexto da generalização, esta pesquisa tem como objetivo propor uma metodologia para a representação das feições de edificações, limites de imóveis e arruamento na escala 1:5.000, por generalização de cartas topográficas na escala 1:2.000. Isto foi feito através da análise das classes de feições na escala reduzida, da identificação dos problemas de representação, e da definição e aplicação dos operadores de generalização cartográfica. Os resultados foram alcançados utilizando o software ArcMap e os operadores de generalização: eliminação, simplificação e amalgamação, de acordo com cada problema de representação detectado. A generalização manual é um processo subjetivo e intuitivo, portanto o resultado depende dos ope- 
radores de generalização e do grau de aplicação destes, e estes fatores são consequentes das decisões tomadas pelo cartógrafo.

Palavras chave: generalização cartográfica, carta topográfica, operadores de generalização.

\section{Introdução}

A generalização cartográfica consiste em reduzir a escala do mapa preservando as características das feições representadas de modo que estas possam ser compreendidas pelo usuário (D’Alge, 2007). Esta redução aumenta o grau de complexidade da carta, pois enquanto a densidade de informações representadas aumenta o espaço reservado à representação continua o mesmo. Como consequência, surgem problemas quantitativos e qualitativos. Assim, deve haver uma preocupação por parte do cartógrafo em representar as informações de forma visível e legível (Taura, 2007). A generalização preserva a legibilidade da representação cartográfica das feições para que a comunicação cartográfica se mantenha eficiente.

O procedimento de generalização pode ser realizado manualmente ou de maneira automática, por meio de algoritmos computacionais. A generalização manual envolve a intuição, experiência e o conhecimento do cartógrafo sobre as feições representadas, seu significado e importância. Deste modo, o profissional determina o que e como será representado na escala menor. Os algoritmos desenvolvidos para a generalização automática demandam um profundo conhecimento teórico e prático, e não exigem o nível de interferência humana como a generalização manual. No Brasil somente os procesos relacionados à generalização semántica são adotados na produção de cartas topográficas em diferentes escalas. Tais cartas topográficas, mesmo quando em diferentes escalas, são produzidas por levantamentos diretos (IBGE, 2013).

Em países em que a produção de cartas topográficas é tradicional e o mapeamento básico é frequentemente atualizado, esse é primeiramente realizado numa escala básica, a partir de levantamentos diretos, e a geração das cartas topográficas em escalas menores se dá através da generalização cartográfica. Por exemplo, o mapeamento da Grã-Bretanha é responsabilidade do Ordnance Survey, que produz cartas topográficas a partir de levantamentos diretos em três escalas base: 1:1.250, 1:2.500 e 1:10.000, e o restante são cartas derivadas e generalizadas destas (João, 1998). A Swiss Society of Cartography (SCC) produz cartas topográficas nas escalas 1:5.000 e 1:10.000, chamadas de cartas bases. A partir destas, mapas topográficos são gerados desde a escala 1:25.000 até 1:1.000.000. Este processo pode ser aplicado em cartas topográficas digitais ou no banco de dados correspondente a escala final da carta. Adquirir e consolidar o conhecimento e experiência na produção de cartas topográficas por generalização cartográfica pode aprimorar o processo de mapeamento topográfico no Brasil. 
Considerando que o tema generalização cartográfica é pouco explorado em pesquisas no Brasil, este trabalho tem por objetivo propor uma metodologia de generalização para as feições de edificações, limites de imóveis e arruamento, por meio da aplicação de operadores de generalização para uso em cartas topográficas de áreas urbanas na escala 1:5.000, derivada da escala 1:2.000, com base no estudo da teoria sobre generalização cartográfica para produção de cartas topográficas desenvolvida em países onde tal conhecimento já está consolidado.

\section{Generalização cartográfica para cartografia topográfica}

Segundo Keates (1973) numa carta topográfica são representadas "todas as feições identificáveis da superfície terrestre, naturais e artificias, para as quais é possível estabelecer uma posição específica, expressa em relação à superfície topográfica". Assim pode-se dizer que o objetivo do mapeamento topográfico é a representação acurada e precisa da posição espacial das feições em função de uma escala prédeterminada. $\mathrm{O}$ autor ainda afirma que "o propósito fundamental das cartas topográficas é representar as feições em suas posições corretas, dentro dos limites da escala".

A representação sistemática do território brasileiro, segundo o Decreto Lei 243 de 1967, deve ser realizada de maneira contínua, homogênea e articulada. No Brasil a produção das cartas topográficas nas escalas-padrão do mapeamento sistemático terrestre é realizada majoritariamento por levantamentos diretos. Nestas situações não são produzidas cartas topgoráficas em diferentes escalas por processo de generalização cartográfica. Uma das consequências da falta de um programa de produção de cartas topográficas por generalização cartográfica é a carência em nosso país de mapas nas diferentes escalas-padrão previstas pelas normas do mapeamento oficial, do território nacional.

Segundo a Swiss Society of Cartography (2002) a generalização cartográfica consiste na seleção e combinação de objetos importantes para a compreensão do mapa, na manutenção da precisão posicional, na preservação das características das feições e na representação destas de modo claro. A Internacional Cartography Association (ICA) define generalização cartográfica como o proceso de seleção e representação simplificada de detalhes em função da escala e do objetivo do mapa.

Os seguintes fatores influenciam a generalização cartográfica: origem do material fonte; escala que determina o tamanho do objeto sobre a carta; condições especiais de legibilidade, relacionadas às condições ambientes para a leitura da carta; especificação de símbolos; escolha das cores adequadas ao tamanho dos símbolos e do meio de visualização; meio de reprodução; e atualização cartográfica (Swiss Society of Cartography, 1977).

Com o surgimento da cartografia digital e a constante evolução dos sistemas de informações geográficas, a generalização passou a ser realizada em meio digital, o 
que produziu novos problemas e, consequentemente novos conceitos à definição deste processo cartográfico (McMaster e Shea, 1992). A generalização manual pode ser realizada, além de em ambiente analógico em cartas impressas, também em ambiente digital em cartas vetorizadas. Ambos os ambientes requerem a intervenção direta do cartógrafo, que define quais feições generalizar, quando e como realizar a generalização. $\mathrm{O}$ processo digital pode ser semiautomático, com interferência do cartógrafo, ou automático, sem intervenção do operador. Os procedimentos automáticos são realizados através de códigos computacionais (Issmael, 2003). A vantagem do processo manual é sua característica holística, ou seja, a visualização dos problemas associados à generalização e a aplicação das transformações necessárias são vistos de modo integrado, enquanto a generalização digital opera com algoritmo computacional. As transformações são tratadas de modo independente e aplicadas numa sequência pré-determinada (McMaster e Shea, 1992).

McMaster e Shea (1992) dividem o processo de generalização cartográfica em três etapas:

1. Objetivos filosóficos: por que generalizar?

2. Avaliação cartométrica: quando generalizar?

3. Transformações espaciais e de atributos: como generalizar?

Os objetivos filosóficos se referem aos motivos que induzem a realização do processo de generalização, os quais incluem a adesão aos princípios básicos da Cartografia, atenção aos requisitos do problema de generalização considerado, e a as exigências e recursos tecnológicos existentes. Segundo McMaster e Shea (1992) as técnicas de generalização são aplicadas para minimizar os efeitos indesejados da redução de escala.

A avaliação cartométrica pode ser definida como uma análise da carta reduzida em busca de fatores que indiquem a necessidade de generalização. McMaster e Shea (1992) afirmam que isto ocorre quando a carta em escala menor não atende aos objetivos propostos no início da sua produção e, portanto, o usuário não consegue compreender o que está representado devido à falta de clareza. Alguns problemas da redução de escalas são:

- Congestionamento, ou seja, alta densidade de símbolos em uma área;

- Coalescência, aproximação excessiva entre símbolos;

- Imperceptibilidade, quando as feições estão abaixo do tamanho mínimo perceptível na carta;

- Conflito, quando a feição e o seu fundo não são compatíveis. 
Estes também são denominadas de condições geométricas (McMaster e Shea, 1992).

As transformações espaciais são realizadas por operadores que alteram a representação dos dados do ponto de vista geográfico ou topológico (McMaster e Shea, 1992). Os operadores de transformação espacial são: simplificação, suavização, agregação, amalgamação, união, colapso, refinamento, exagero, realce e deslocamento. As transformações de atributos são realizadas pelos operadores de classificação e simbolização, os quais se referem à manipulação de características secundárias. Neste trabalho, apenas operadores de transformação espacial foram aplicados e estes são definidos e exemplificados na Tabela 1. Kraak e Ormeling (2010) incluem os operadores de fusão e seleção nas transformações de atributos, pois estes podem alterar a simbologia das feições representadas.

Tabela 1

Operadores de Transformação Espacial

Operadores
Eliminação: elimina características das feições de
forma seletiva.
Simplificação: eliminação de pontos baseada de
acordo com sua importância para a manutenção
das características ou da forma descritiva de fei-
ções.
Amalgamação: união de polígonos, eliminando seus
limites, para manter a característica geral da regi-
ão.

Fonte: Adaptado de McMaster e Shea (1992).

\section{Metodologia}

Com objetivo de testar a proposta de metogologia de generalização a ser adotada no Brasil, foram realizados os experimentos descritos a seguir.

Os materiais empregados foram as bases cartográficas de Pinhão e do bairro Centro Histórico de Paranaguá, ambos os municípios localizados no estado do Paraná. As características destas bases são: sistema geodésico SAD-1969, projeção cartográfica UTM zona $22^{\circ} \mathrm{S}$, escala 1:2.000, datadas de 1996. O proceso da generalização foi realizado manualmente usando as funções do software ArcMap.

A metodologia desta pesquisa é composta por sete etapas: 
1. Edição das cartas topográficas;

2. Definição das classes a serem analisadas;

3. Redução geométrica das cartas de 1:2.000 para 1:5.000;

4. Identificação visual dos problemas de representação;

5. Definição dos operadores de generalização;

6. Aplicação dos operadores de generalização, e

7. Avaliação do resultado.

\section{Descrição das áreas de estudo}

A Tabela 2 apresenta dados referentes aos dois municípios cujas cartas topográficas foram analisadas.

Tabela 2

Dados dos municípios analisados

\begin{tabular}{lcccc}
\hline Municipio & Área Total $\left(\mathrm{km}^{2}\right)$ & $\begin{array}{c}\text { População } \\
\text { (habitantes) }\end{array}$ & $\begin{array}{c}\text { Densidade } \\
\text { demográfica } \\
\left(\text { hab/ } / \mathrm{km}^{2}\right)\end{array}$ & $\begin{array}{c}\text { População } \\
\text { urbana } \\
\text { (habitantes) }\end{array}$ \\
\hline Paranaguá & 826,674 & 140.469 & 169,92 & 135.386 \\
Pinhão & $2.001,588$ & 30.208 & 15,09 & 15.317 \\
\hline
\end{tabular}

Fonte: IBGE (2010).

O município de Pinhão localiza-se na região central do estado do Paraná e tem sua economia voltada para a agricultura. Praticamente metade da população é rural, enquanto a área urbana é igual a $10,22 \mathrm{~km}^{2}$. A ocupação urbana se concentra em torno da Rodovia Estadual PR-170. Paranaguá, município localizado no litoral do estado, possui regiões com ocupação consolidada, como o bairro Centro Histórico e a Ilha dos Valadares. As áreas definidas no zoneamento do município como zonas de desenvolvimento econômico e de comércio e serviços apresentam concentração de edificações e estão localizadas em torno da Rodovia Federal BR-277. A Figura 1 apresenta a localização do estado do Paraná no Brasil e dos municípios de Pinhão e Paranaguá, no Paraná.

\section{Edição das cartas topográficas}

A edição foi necessária devido as bases cartográficas utilizadas estarem armazenadas em formato $d x f$, e o formato padrão do software ArcMap ser shapefile. Na base de dados original não há arquivos individuais para cada classe, todas estão representadas numa única camada, sendo apenas diferenciadas pelo tipo de elemento gráfico da estrutura vetorial, se polígono, polilinha, ou ponto, além da toponímia. Deste modo, novos arquivos foram criados para cada classe, de acordo com sua respectiva denominação e código identificador, na escala 1:2.000. 


\section{Definição das classes a serem analisadas}

As classes analisadas são: edificações, limites de imóveis e vias. Estas feições foram definidas como os elementos dos estudos de caso desta pesquisa porque são as feições que compõem o mapeamento urbano em grandes escalas e que são fundamentais para as atividades do Planejamento Urbano. As atividades de Planejamento Urbano foram definidas como o principal critério para a definição das feições, para as quais esta metodologia está sendo proposta, porque o PARANACIDADE é o parceiro das pesquisas desenvolvidas no grupo de pesquisa "Cartografia e Sistemas de Informações Geográficas", voltadas às questões do mapeamento topográfico em grande escala, incluindo as pesquisas em generalização cartográfica. $\mathrm{O}$ PARANACIDADE é um órgão ligado à Secretaria de Desenvolvimento Urbano do estado do Paraná, e é responsável pelo desenvolvimento regional e urbano dos municípios por meio de assistência técnica e treinamento em administração e gestão urbana (Nalini, 2005).

Os projetos cartográficos desenvolvidos pelo PARANACIDADE devem apresentar os imóveis das áreas urbanas, as quadras, o sistema viário e os loteamentos dos municípios, por isso tais classes foram escolhidas. A classificação das edificações se dá do seguinte modo: residenciais, comerciais, públicas, de saúde, de ensino, industriais, religiosas e clubes. Para as classes de limites de imóveis e vias não há classificação.

\section{Redução geométrica das cartas de 1:2.000 para 1:5.000}

A escala das cartas foi reduzida de 1:2.000 para 1:5.000 sem que a representação das feições fosse alterada. Isto foi feito através da alteração da escala no campo correspondente na barra de ferramentas do ArcMap. Esta redução é necessária para que as cartas possam ser analisadas na escala reduzida e possíveis problemas de representação possam ser identificados. Tais problemas correspondem às condições específicas descritas por McMaster e Shea (1992) que indicam quando a generalização deve ser aplicada. Entre tais condições pode-se citar a concentração de feições numa determinada área da carta topográfica e a proximidade excessiva entre as feições de edificações, situações que prejudicam sua legibilidade.

As Figuras 2 e 3 ilustram o resultado da redução direta da escala 1:2.000 para 1:5.000, em regiões do município de Paranaguá e de Pinhão. A Figura 2 ilustra o recorte de uma área da carta do Centro Histórico de Paranaguá, nas escalas 1:2.000 (a) e 1:5.000 (b). A Figura 3 apresenta um recorte da carta do município de Pinhão na escala original (a) e na escala reduzida (b). As feições representadas nestas cartas incluem: edificações comerciais, industriais, públicas, escolares, igrejas, de saúde, jardins, canteiro central, eixo viário, limites de imóveis e arruamento. As edificações residenciais estão representadas somente na carta do Centro Histórico. 

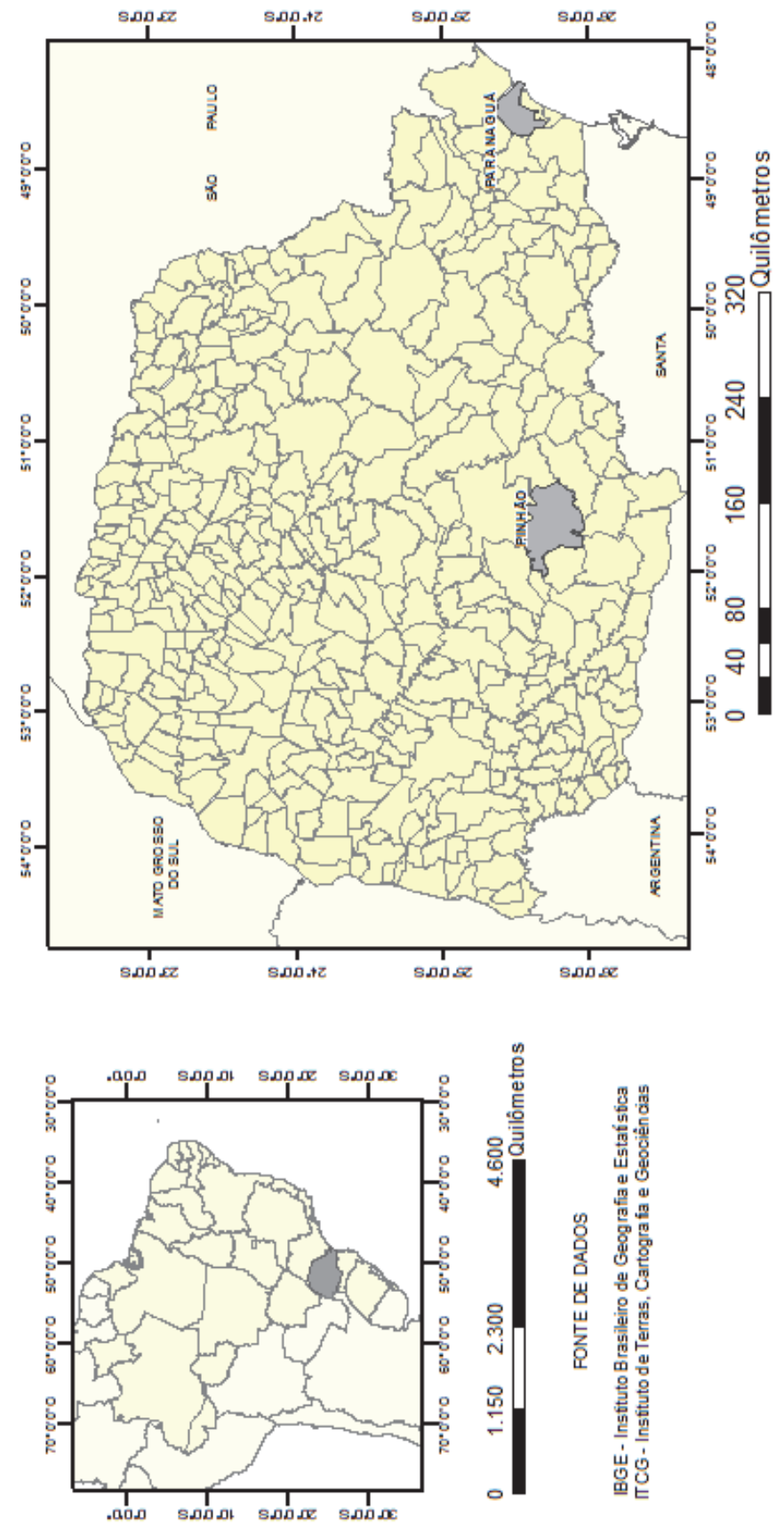

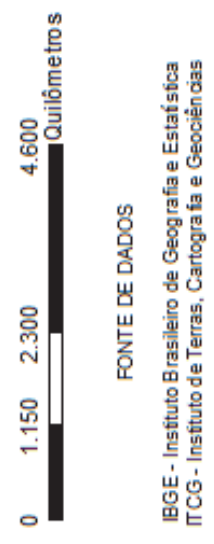

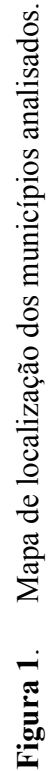




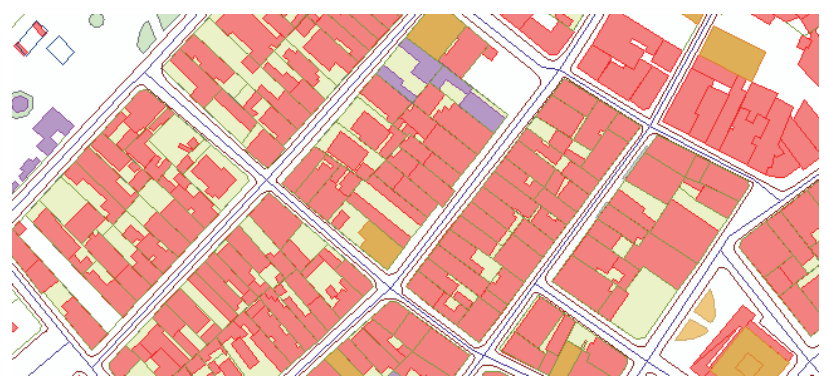

(a)

(b)

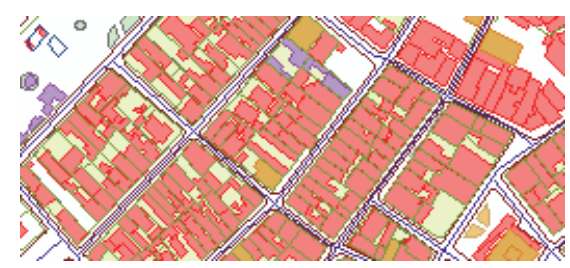

Figura 2. Recorte da carta do Centro Histórico de Paranaguá na escala 1:2.000 (a) e 1:5.000 (b).

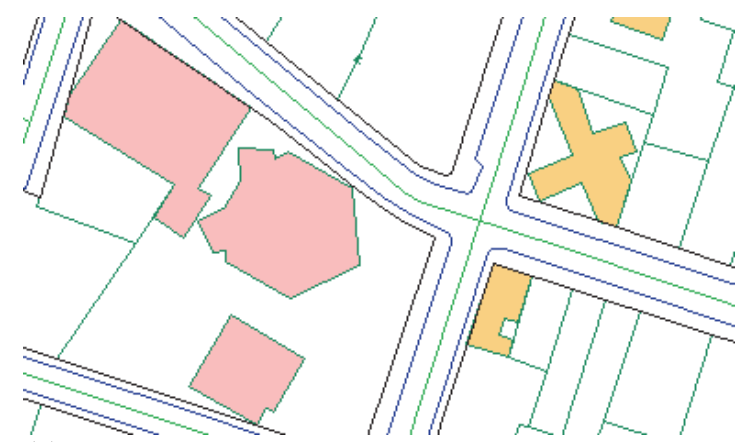

(a)

(b)

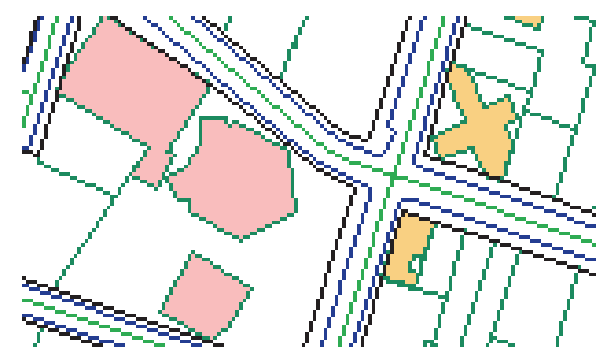

Figura 3. Recorte da carta de Pinhão na escala 1:2.000 (a) e 1:5.000 (b). 


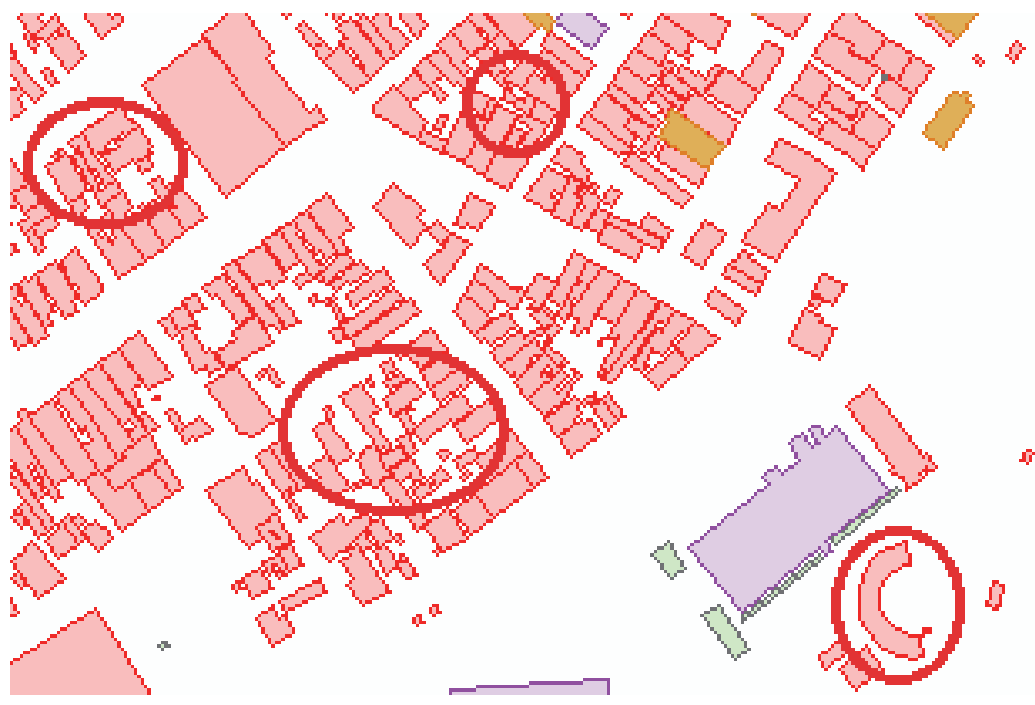

Figura 4. Recorte da carta do Centro Histórico de Paranaguá na escala 1:5.000 com a identificação de áreas com problemas de representação.

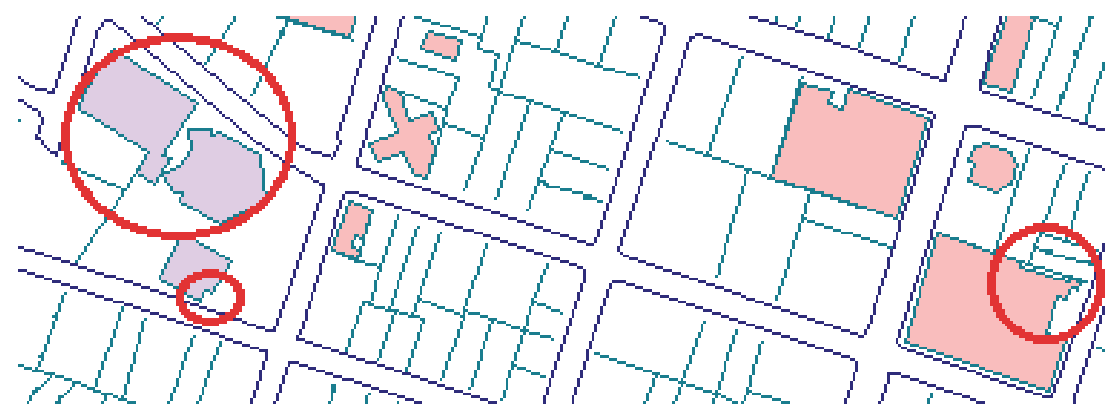

Figura 5. Recorte da carta de Pinhão na escala 1:5.000 com a identificação de áreas com problemas de representação.

\section{Identificação visual dos problemas de representação}

Os problemas de representação se referem às condições geométricas descritas por McMaster e Shea (1992), e são constituintes da avaliação cartométrica. Tais condições, além de indicar a necessidade de generalização, podem auxiliar na determinação de quais operadores devem ser aplicados para manter a comunicação cartográfica eficiente. As cartas reduzidas foram analisadas visualmente, em meio digital, para a identificação de situações que interferem na leitura da carta. A Figura 4 representa um recorte da carta topográfica do Centro Histórico de Paranaguá com 


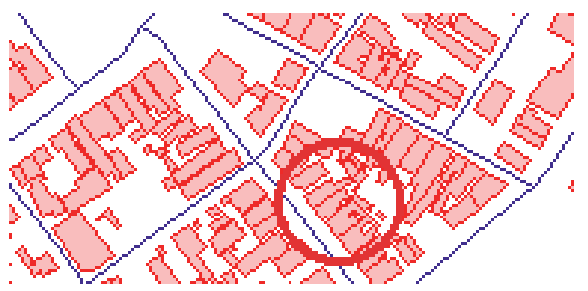

(a)

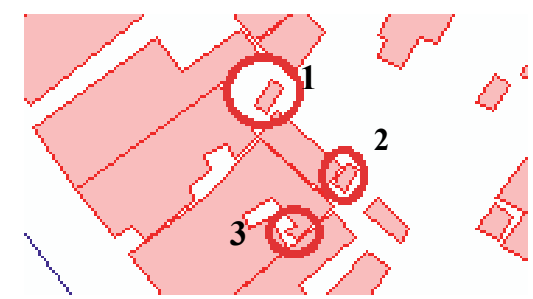

(b)

Figura 6. Exemplos dos problemas de imperceptibilidade e aproximação excessiva entre feições.

(a)

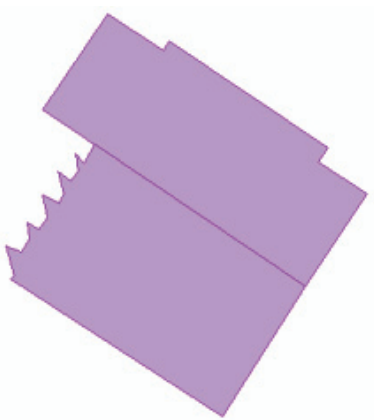

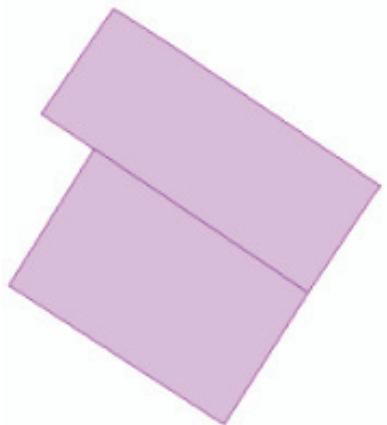

(b)

Figura 7. Edificação pública antes (a) e após sua simplificação (b).

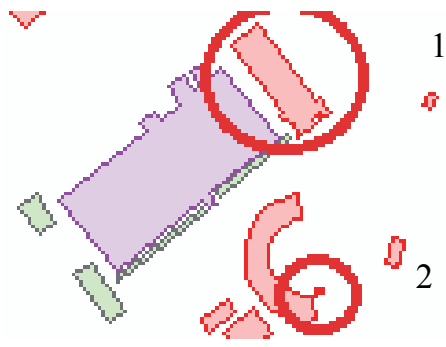

(a)

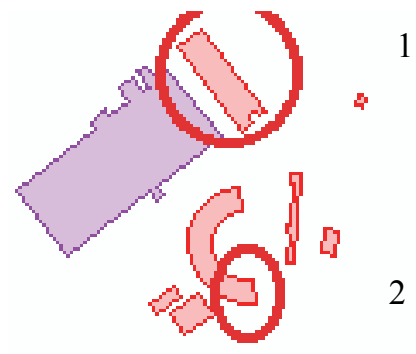

(b)

Figura 8. Exemplo de edificações generalizadas na carta do Centro Histórico de Paranaguá. 
destaque para as áreas que apresentam problemas de representação, tal como a dificuldade de identificação de cada edificação individual e dos detalhes na representação das edificações. Os limites de imóveis e o arruamento não estão representados para facilitar a visualização das edificações, fonte principal dos problemas de representação.

Conforme mencionado anteriormente, na carta topográfica de Pinhão não estão representadas as edificações residenciais. Por este motivo, esta carta não apresenta a mesma quantidade e os mesmos problemas de representação que a carta topográfica do Centro Histórico de Paranaguá. A dificuldade de visualização refere-se à identificação e distinção dos detalhes na representação das edificações, como a Figura 5 ilustra.

Em seguida, as edificações foram analisadas com relação aos detalhes de suas representações, seus tamanhos e espaçamentos entre feições. Tais características foram medidas com auxilio da ferramenta measure. Quando o comprimento do lado de uma edificação está abaixo do valor mínimo de representação na escala (Tabela 3), esta deve ser eliminada. Se a edificação apresentar algum detalhe na sua representação que não seja igual ou maior do que o valor mínimo, recomenda-se a simplificação do polígono desta edificação. Tais valores foram definidos por pesquisas baseadas em testes de percepção visual realizados por Taura (2007).

A análise visual das cartas resultou na detecção de três condições geométricas: congestionamento, coalescência e imperceptibilidade.

Tabela 3

Símbolos e dimensões mínimas utilizadas para detectar problemas de representação

\begin{tabular}{lcc|c|c|}
\hline & Tamanho Mínimo & 5.000 & \multicolumn{1}{c}{ Exemplo } \\
\hline $\begin{array}{l}\text { Espaçamento entre } \\
\text { áreas }\end{array}$ & $0,25 \mathrm{~mm}$ & $1,25 \mathrm{~m}$ & $0,25 \mathrm{~mm}$ \\
$\begin{array}{l}\text { Área com detalhes } \\
\text { no polígono }\end{array}$ & $0,3 \mathrm{~mm}$ & $1,5 \mathrm{~m}$ & \\
$\begin{array}{l}\text { Espaçamento entre } \\
\text { área e linha }\end{array}$ & $0,25 \mathrm{~mm}$ & $1,25 \mathrm{~m}$ & $0,25 \mathrm{~mm}$ \\
$\begin{array}{l}\text { Comprimento do } \\
\text { lado do quadrado } \\
\text { preenchido }\end{array}$ & $0,3 \mathrm{~mm}$ & $1,5 \mathrm{~m}$ & $0,3 \mathrm{~mm}$ \\
\hline
\end{tabular}

Fonte: $\quad$ Adaptado de Taura (2007). 


\section{Definição e aplicação dos operadores de generalização}

Com base nos problemas identificados na etapa anterior, foram definidos quais operadores devem ser utilizados para preservar a legibilidade das cartas, os quais podem ser: eliminação, simplificação e amalgamação, nesta ordem. A eliminação deve ser aplicada quando o comprimento do lado de alguma edificação está abaixo do tamanho mínimo, sendo assim imperceptível aos olhos humanos. A simplificação se faz necessária pelo mesmo princípio: uma edificação apresenta detalhes na sua representação cujos tamanhos estão abaixo do valor mínimo, ou não são visíveis. Além da imperceptibilidade, os detalhes nos polígonos das edificações contribuem para a condição geométrica de congestionamento. A amalgamação deve ser empregada quando o espaçamento entre as feições está abaixo da distância mínima e do seguinte modo: sempre a feição menor será deslocada eliminando o espaço entre esta e a feição maior, sem sofrer alteração no ângulo e direção da sua representação.

A Figura 6(a) destaca uma região da carta do Centro Histórico de Paranaguá, na escala 1:5.000, na qual foram detectados os problemas de representação relacionados a imperceptibilidade e a coalescência. A Figura 6(b) está na escala 1:1.000 para que fosse possível identificar quais feições devem ser generalizadas. Os exemplos 1 e 2 apresentam as condições geométricas de imperceptibilidade e coalescência. Devido ao tamanho do lado destas edificações, optou-se pela aplicação do operador de eliminação. $\mathrm{O}$ exemplo 3 corresponde ao problema de imperceptibilidade relacionado ao detalhe da edificação, o qual não é visível na escala 1:5.000. Deste modo é necessário simplificar a feição, eliminando este detalhe.

\section{Resultados}

Os operadores de generalização foram aplicados em todas as edificações das duas cartas topográficas. Em virtude da densidade de edificações que apresentam detalhes nas suas representações, o operador de simplificação foi o mais utilizado.

A Figura 7 ilustra uma edificação pública do município de Pinhão antes da generalização (a), representada por uma área cujas linhas limitantes apresentam vários detalhes, e a edificação após a generalização (b). Como estes não seriam perceptíveis, foram eliminados e a área foi simplificada. A figura está numa escala ampliada para facilitar a visualização.

A Figura 8 apresenta a identificação de duas feições generalizadas na carta topográfica do Centro Histórico de Paranaguá. O exemplo 1 refere-se a uma edificação cujos detalhes na representação foram simplificados. Pode-se observar que os detalhes no desta edificação, na carta original (a) são visíveis, porém o comprimento destes detalhes está abaixo do tamanho mínimo, neste caso $1,5 \mathrm{~m}$. Assim, foi utilizado o operador de simplificação para manter a comunicação cartográfica eficiente, Figura 8(b). O exemplo 2 ilustra uma feição cujo tamanho a torna imper- 
ceptível aos olhos humanos e cuja distância em relação à edificação vizinha caracteriza a condição geométrica de coalescência, pois há aproximação excessiva entre estas feições e não é possível visualizar o espaçamento entre elas Figura 8(a). Neste caso, foi aplicado o operador de eliminação Figura 8(b).

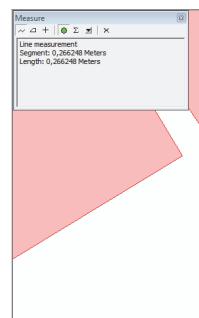

(a)
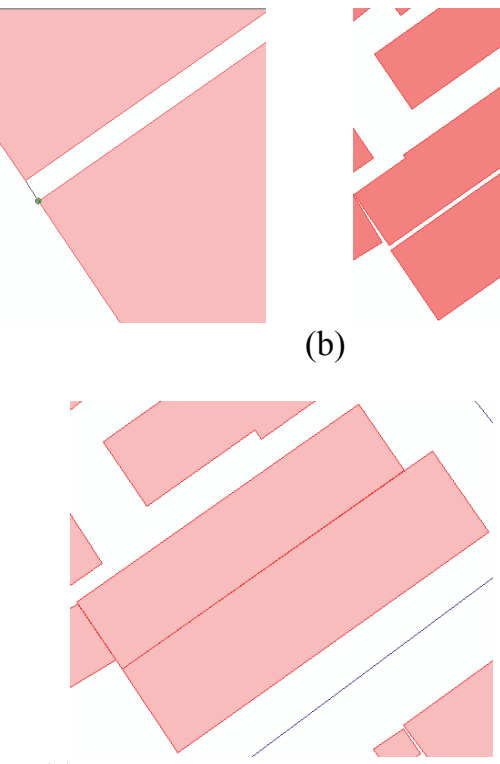

(c)

(b)

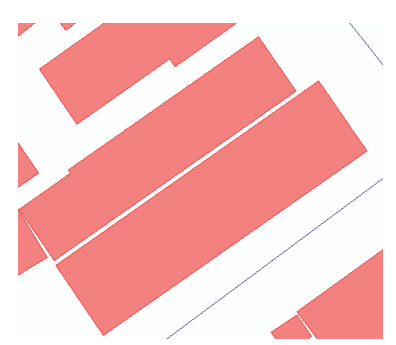

Figura 9. Espaçamento entre as edificações abaixo do valor mínimo (a), edificações residenciais a serem generalizadas (b) e edificações residenciais após a generalização (c).

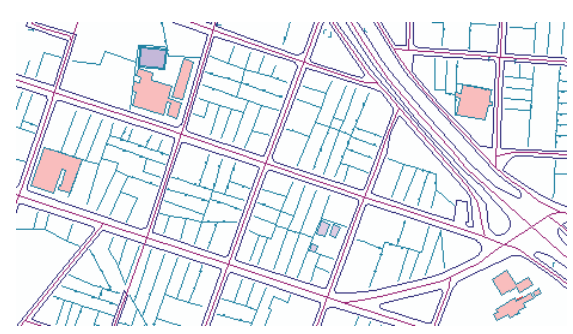

(a)

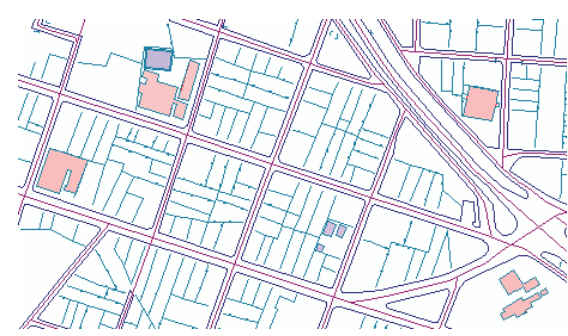

(b)

Figura 10. Carta original (a) e carta generalizada (b) de Pinhão. 
As edificações residenciais com espaçamento menor que $0,25 \mathrm{~mm}$ foram combinadas de forma que o limite de propriedade entre elas formasse uma única linha, conforme a Figura 9. O espaçamento entre as duas edificações está abaixo do valor mínimo de $0,25 \mathrm{~mm}$ ou 1,25 m (Figura 9a), assim, estas devem ser combinadas (Figura 9c).

A Figura 10 (a) apresenta um recorte da carta original de Pinhão e a Figura 10 (b) refere-se à carta generalizada. Visto que somente o operador de simplificação foi aplicado nas edificações e nos limites de imóveis, as mudanças não são visíveis na escala reduzida.

Um recorte da carta original do Centro Histórico de Paranaguá (a) e a carta generalizada (b) é mostrado na Figura 11. Os operadores utilizados foram o de simplificação, eliminação e amalgamação. Pode-se discernir as edificações simplificadas e quais foram eliminadas, no entanto o mesmo não ocorre na visualização de quais feições o operador de amalgamação foi aplicado.

Os limites de imóveis foram generalizados seguindo o mesmo padrão das edificações, pois as linhas dos polígonos das edificações muitas vezes coincidem com os limites das imóveis. A Figura 12 ilustra esta situação. Identificada uma edificação

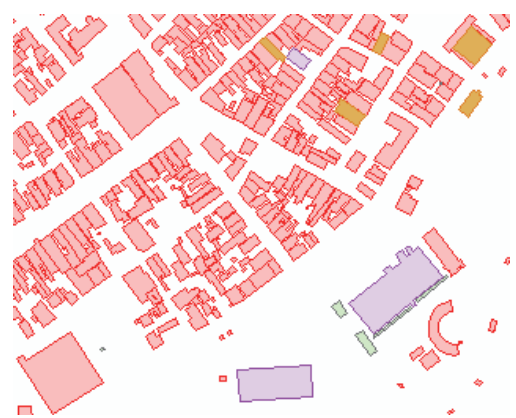

(a)

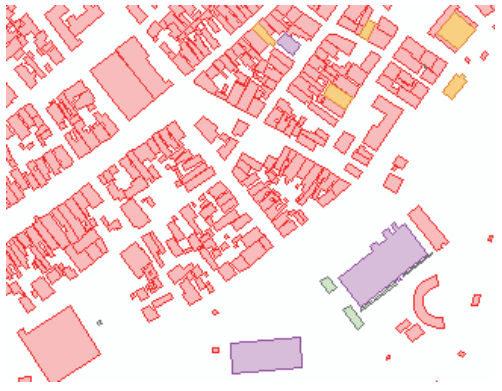

(b)

Figura 11. Recorte da carta original (b) e da carta generalizada (b) do Centro Histórico de Paranaguá.

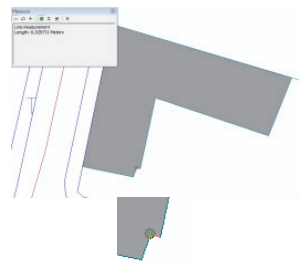

(a)

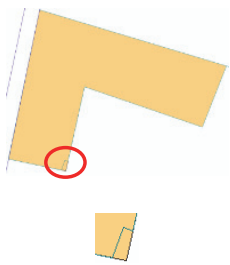

(b)

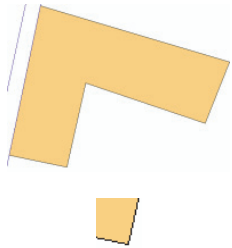

(c)

Figura 12. Simplificação do limite de imóveis de acordo com a edificação correspondente. 
industrial que apresenta detalhe na representação cujo tamanho está abaixo do valor mínimo, 1,5 m (a), o operador de simplificação foi aplicado. No entanto, após a simplificação da edificação, nota-se que o limite de imóveis original não corresponde mais a feição generalizada (b). Devido a isto, o operador de simplificação foi novamente aplicado (c).

\section{Conclusão}

O principal objetivo desta pesquisa foi definir uma metodologia de generalização cartográfica para feições urbanas, baseada em trabalhos já desenvolvidos no Programa de Pós-Graduação em Ciências Geodésicas da UFPR. Isto foi alcançado através da aplicação dos conceitos apresentados sobre generalização cartográfica e com resultados obtidos na aplicação do conhecimento adquirido pela pesquisa preliminar sobre generalização cartográfica desenvolvida em países que já dominam a produção de cartas topográficas através da generalização automática.

A generalização cartográfica é um processo trabalhoso, quando feito manualmente, e o resultado depende do cartógrafo que a faz, pois envolve a intuição deste profissional que irá avaliar o que é importante na carta e por isso deve ser representado. Os operadores de generalização não seguem uma regra exatamente específica, pois ainda não há regras claras sobre como aplicá-los. A avaliação cartométrica auxilia, não somente na indicação da necessidade de generalização, mas na identificação de quais operadores podem ser empregados para eliminar ou minimizar as condições geométricas detectadas nas cartas reduzidas.

A generalização manual realizada em ambiente digital, como realizada neste trabalho, apresenta vantagens como a análise holística dos problemas de representação, a aplicação dos operadores e a posterior avaliação de cada feição representada individualmente. A redução geométrica das cartas topográficas permite a identificação dos problemas de representação. Tendo conhecimento destes problemas é possível determinar quais operadores de generalização devem ser aplicados para manter a comunicação cartográfica eficiente na carta reduzida. Assim, após a detecção dos problemas, definiu-se os operadores de generalização a serem aplicados. A avaliação das cartas reduzidas generalizadas permite afirmar que os operadores adotados foram aplicados corretamente e que, com relação as feições analisadas, os problemas de representação foram solucionados.

\section{Bibliografia}

Brasil (1967). "Decreto-Lei n 243, de 28 de fevereiro de 1967. Fixa as diretrizes e bases da Cartografia Brasileira e dá outras providências", Diário Oficial da União, Brasília. 
D’alge, J.C.L. (2007). “Generalização Cartográfica em Sistemas de Informação Geográfica: Aplicação aos Mapas de Vegetação da Amazônia Brasileira", Tese de Doutorado em Engenharia, Escola Politécnica da Universidade de São Paulo, São Paulo, 150 pp.

João, E.M. (1998). Causes and consequences of Map Generalisation, Taylor and Francis, 1a. ed. London School of Economics, 266 pp.

Firkowski, H. (2002). "Generalização Cartográfica de Grades Retangulares Regulares Baseada na Teoria Matemática da Comunicação", Tese de Doutorado em Ciências Geodésicas, Universidade Federal do Paraná, Curitiba, 136 pp.

IBGE, Instituto Brasileiro de Geografia e Estatística (2010). Censo 2010, Brasil. - (2013). Mapeamento Topográfico, Brasil.

Issmael, L.S. (2003). "Generalização Cartográfica: Determinação de Operadores e de Escalas Catastróficas", Dissertação de Mestrado em Ciências em Engenharia Cartográfica, Instituto Militar de Engenharia, Rio de Janeiro, 250 pp.

Kraak, M.; Ormeling, F. (2010). Cartography: Visualization of Spatial Data, $3 \mathrm{a}$. ed., Great Britain, Pearson Education Limited, Londres, 198 pp.

Lecordix, F. (2011). "Cartographic Generalisation Processo on French Topographic Mapping", VII Colóquio Brasileiro de Ciências Geodésicas, Curitiba.

Lopes, J. (2005). "Generalização Cartográfica", Dissertação de Mestrado em Ciências e Engenharia da Terra, Universidade de Lisboa, Lisboa, 120 pp.

McMaster, R.B. e K.S. Shea (1992). Generalization in Digital Cartography, 1a. ed. Washington, Association of American Geographers, 133 pp.

Nalini, V.T. (2005). "Avaliação Cartométrica da Base Cartográfica Digital Adequada à Gestão Urbana Derivada por Generalização Cartográfica a Partir da Escala de Origem 1:2.000”, Dissertação de Mestrado em Ciências Geodésicas, Universidade Federal do Paraná, Curitiba, 106 pp.

SCC, Swiss Society of Cartography (1977). Cartographic Generalization, Cartographic Publication Series no. 2, $61 \mathrm{pp}$.

(2002). Maps Graphics and Generalisation, Cartographic Publication Series no. $17,126 \mathrm{pp}$.

Taura, T.A. (2007). "Estudo da Sim para Cartas nas Escalas 1:2.000, 1:5.000 e 1:10.000 de Mapeamento Urbano do PARANACIDADE e Generalização Cartográfica", Dissertação de Mestrado em Ciências Geodésicas, Universidade Federal do Paraná, Curitiba, 93 pp. 